\title{
Eribulin mesylate in the treatment of metastatic breast cancer
}

\author{
This article was published in the following Dove Press journal: \\ Biologics:Targets and Therapy \\ 10 January 2012 \\ Number of times this article has been viewed
}

\author{
Sarika Jain \\ Tessa Cigler \\ Department of Medicine, \\ Weill Cornell Medical College, \\ New York, NY, USA
}

Correspondence: Tessa Cigler Weill Cornell Medical College Iris Cantor Breast Center, 425 East 6I st Street, 8th Floor, New York, NY 10065, USA

$\mathrm{Tel}+\mid$ 2I $282 \mid 0736$

$\mathrm{Fax}+\mid$ 212 82| 0796

Email tec9002@med.cornell.edu
Abstract: The treatment of metastatic breast cancer (MBC) has become increasingly challenging as the primary goals of therapy include prolonging life without added toxicity. While multiple agents are approved for the therapy of $\mathrm{MBC}$, there is no standard approach for therapy beyond the second-line. Eribulin mesylate, an analog of the marine sponge halichondrin B, is a non-taxane microtubule dynamics inhibitor with a mechanism of action distinct from other tubulin-targeted drugs. Based on a significant extension in overall survival seen in a Phase III clinical trial, eribulin was approved for third-line therapy in MBC patients following anthracycline and taxane failure. Eribulin has a manageable toxicity profile and a low incidence of peripheral neuropathy. In this review, we discuss the natural source of eribulin, pharmacology, mode of action, preclinical and clinical data, and patient-focused perspectives.

Keywords: eribulin, metastatic breast cancer, microtubule

\section{Introduction}

Breast cancer is the most common malignancy affecting women worldwide. In 2011, an estimated 1,383,500 individuals will be diagnosed with breast cancer and 484,400 will die from the disease. ${ }^{1}$ In the US alone, $5 \%$ of patients presenting with breast cancer will have metastatic disease, and $20 \%$ of patients with early-stage breast cancer will develop a recurrence over 10 years after adjuvant systemic treatment. ${ }^{2,3}$ Treating metastatic breast cancer (MBC) has become increasingly complex, as oncologists attempt to strike a balance between prolonging survival and minimizing toxicity. Despite many available chemotherapeutic options, guidelines do not exist on how best to sequence or combine them. Moreover, there is little good quality evidence on later lines of therapy in women who fail two or more chemotherapeutic regimens.

Several chemotherapeutic agents have been approved for pretreated MBC and include capecitabine (Xeloda), ixabepilone (Ixempra), and most recently eribulin mesylate (Halaven, E7389) based on Phase III data. Capecitabine, an oral fluoropyrimidine, when administered with docetaxel, prolonged overall survival (OS) in anthracycline-pretreated MBC patients; the median OS was 14.5 months in the combination group vs 11.5 months in the docetaxel-treated group (HR: $0.775,95 \%$ confidence interval [CI]: $0.634-0.947, P=0.0126)$. Gastrointestinal side effects and hand-foot syndrome were more common in the capecitabine arm occurring in $>60 \%$ of the patients. ${ }^{4}$ Ixabepilone, a microtubule-targeted epothilone analog, improved progression-free survival (PFS) in combination with capecitabine relative to capecitabine alone (median 5.8 vs 2.4 months, HR: 0.75, 95\% CI: $0.64-0.88, P=0.0003$ ) in patients with $\mathrm{MBC}$ treated with anthracycline and taxane therapy. The ixabepilone 
arm reported $66 \%$ neuropathy (22\% grade $3 / 4)$ and $68 \%$ grade $3 / 4$ neutropenia. ${ }^{5}$ A confirmatory trial similarly demonstrated a significant improvement in PFS with ixabepilone plus capecitabine compared to capecitabine alone but not in OS, the primary endpoint of the study, except for patients with an impaired Karnofsy's performance score (KPS) of $70 \%$ to $80 \%$. Neutropenia ( $92 \%$ all grades, $72 \%$ grade 3/4) was considerable though febrile neutropenia was uncommon (7\%). Peripheral neuropathy in the ixabepilone group (66\% all grades, $24 \%$ grade $3 / 4$ ) led to study discontinuation in $26 \%$ of patients but was reversible. ${ }^{6}$ In November 2010, the US Federal Drug Administration (FDA) approved eribulin mesylate as third-line treatment for MBC refractory to anthracyclines and taxanes based on a Phase III clinical trial showing significantly increased overall survival compared to treatment of investigator's choice. ${ }^{7}$ Eribulin is the only drug to date that has been shown to prolong survival of heavily pretreated MBC patients when administered as monotherapy. That is, the survival benefit seen with both capecitabine and ixabepilone has never been investigated in adequately powered single-agent studies.

\section{Introduction to eribulin}

In 1986, Hirata and Uemura extracted halichondrin B, a large polyether macrolide, from a rare marine Japanese sponge, Halichondria okadai. ${ }^{8}$ Based on its potent anticancer activity in preclinical models, it was further evaluated in the National Cancer Institute drug evaluation program against other known antimitotic and cytotoxic drugs. ${ }^{9}$ The antiproliferative effects of halichondrin B were found to be similar to other antitubulin agents but its mode of action was remarkably distinct. ${ }^{9,10}$ Despite its impressive in vitro and in vivo anticancer activity, the natural source was not available in sufficient quantity for drug development. In 1998, the biologically active part of the drug was discovered to reside in the macrocyclic lactone C1-C38 moiety, and a completely synthetic and structurally simplified derivative with retained high potency of its parent compound was developed..$^{10,11}$

\section{Eribulin: pharmacology and mechanism of action}

Eribulin inhibits cancer cell proliferation by binding tubulin and destabilizing microtubule dynamics. ${ }^{12}$ At nanomolar concentrations, eribulin works through an end-poisoning mechanism by inhibiting the growth phase of microtubule dynamic instability in interphase cells. Tubulin is sequestered into nonfunctional aggregates, leading to an irreversible arrest at $\mathrm{G}_{2}-\mathrm{M}$ phase and ultimately apoptosis after prolonged mitotic blockade. Other anti-microtubule agents such as paclitaxel and vinblastine induce mitotic blockade and apoptosis in cancer cells similar to eribulin, however the precise interactions between eribulin and tubulin were found to be unique. By binding to the interdimer interface or the $\beta$-tubulin subunit alone, eribulin inhibits only microtubule growth with no effect on shortening, while taxanes and vinca alkaloids suppress both the growth and shortening phases of microtubule dynamic instability. ${ }^{10,12-16}$ This novel tubulin-based mechanism of eribulin may explain its ability to overcome taxane resistance and have wider anti-cancer activity both in the lab and in the clinic.

The mechanistic basis for the anticancer effects of eribulin was demonstrated in eribulin-treated human lymphoma and prostate cancer cell lines. Increasing numbers of hypodiploid cells were seen after eribulin treatment, suggesting the initiation of apoptosis after prolonged mitotic blockade. Biochemical correlates of apoptosis revealed phosphorylation of the anti-apoptotic protein Bcl-2, mitochondrial cytochrome c release, proteolytic activation of caspase-3 and -9, and cleavage of the caspase-3 substrate poly (ADP-ribose) polymerase (PARP). Detection of cytochrome $\mathrm{c}$ and caspase- 9 after eribulin treatment indicated that the mitochondrial apoptotic pathway was activated, a mechanism most commonly associated with chemotherapy response. ${ }^{15}$

The pharmacokinetics of eribulin is linear and dosedependent with a rapid volume of distribution of $48 \mathrm{~L} / \mathrm{m}^{2}$ to $114 \mathrm{~L} / \mathrm{m}^{2}$, slow to moderate clearance of $1.16 \mathrm{~L} /$ hour $/ \mathrm{m}^{2}$ to $2.42 \mathrm{~L} /$ hour $/ \mathrm{m}^{2}$, and slow triphasic elimination with a prolonged terminal half-life ranging from 34 to 48 hours over the dose range of 0.25 to $1.4 \mathrm{mg} / \mathrm{m}^{2}$. Pharmacokinetic profiles were similar between day 1 and day 8 doses. At the maximum tolerated dose (MTD), plasma levels of eribulin were above concentrations required for in vitro cytotoxicity for $>1$ week. Renal excretion is minimal with $5 \%-11 \%$ of the administered dose recovered in the urine. ${ }^{17-19} \mathrm{~A}$ Phase I trial in patients with renal dysfunction $(20-40 \mathrm{~mL} /$ minute, Cockroft-Gault, not requiring dialysis) demonstrated tolerance at full doses of eribulin. ${ }^{20}$ Conversely, in a dedicated hepatic impairment study, liver dysfunction decreased clearance and prolonged elimination half-life, resulting in increased eribulin exposure. Though eribulin was well tolerated and safe in this study, hepatic impairment warrants adjustment of eribulin dosing. ${ }^{21}$ Metabolism of eribulin is minimal and there are no major human metabolites of eribulin. While eribulin is primarily metabolized by CYP3A4, it does not inhibit or induce CYP3A4 activity 
at clinically relevant concentrations in vitro nor affect the metabolism of other CYP3A4-mediated agents including tamoxifen and paclitaxel. ${ }^{22} \mathrm{~A}$ drug-drug interaction trial demonstrated that ketoconazole, a strong CYP3A4 inhibitor, did not affect eribulin clearance. ${ }^{23}$ Eribulin is also a substrate and weak inhibitor of the P-glycoprotein (PgP) drug efflux transporter, with less sensitivity to PgP-mediated multidrug resistance in vitro. ${ }^{24}$

\section{Preclinical studies}

Eribulin has impressive in vitro and in vivo activity with similar potency to its natural parent compound. Eribulin demonstrated in vitro inhibition at sub-nanomolar concentrations against several human cancer cell lines including breast cancer (MDA-MB-435), colon cancer (COLO 205, DLD-1), and prostate cancer (LNCaP, DU 145) with greater potency than vinblastine and paclitaxel. When eribulin was tested in vivo in the $0.05-1 \mathrm{mg} / \mathrm{kg}$ range against human tumor xenograft models including breast, colon, and ovarian cancer, significant anti-tumor effects were achieved. Complete tumor regressions and long-term suppression of tumor regrowth were observed. Notably, the in vivo therapeutic window of eribulin was unusually wide for a cytotoxic drug, with $>95 \%$ tumor suppression over a four-fold dosing range without evidence of toxicity. Eribulin showed superior efficacy at lower doses compared to paclitaxel at empirically determined MTD. ${ }^{10}$ Moreover, eribulin retained essentially full in vitro potency in paclitaxel-resistant human ovarian cancer cell lines harboring $\beta$-tubulin mutations, suggesting that eribulin may be effective in taxane-refractory disease. ${ }^{14}$ In breast cancer cell lines, a significant correlation was demonstrated between higher levels of $\beta I I I-t u b u l i n$ expression, which is associated with resistance to tubulin-targeted agents, and sensitivity to eribulin. ${ }^{25}$

\section{Phase I studies}

The remarkable preclinical activity of eribulin led to the clinical evaluation of eribulin in a variety of tumor types (Table 1). Reported in abstract form, the California Cancer Consortium completed the first Phase I trial with eribulin, using a rapid titration design with real-time pharmacokinetics (PK) to guide dose escalation. Forty patients with refractory or advanced solid tumors were enrolled and 38 patients received eribulin as a weekly 1-2 minute intravenous (IV) bolus three of 4 weeks, starting at $0.125 \mathrm{mg} / \mathrm{m}^{2} /$ week. Patients were continued on a standard $3 \times 3$ dose escalation schedule until grade 2 or higher toxicities were observed. Median age was 61 years, and KPS was greater than $70 \%$ in 31 of 38 patients. The most common primary tumor sites were lung (nine patients) and breast (four). Rapid escalation ended with a grade 3 alkaline phosphatemia at $0.5 \mathrm{mg} / \mathrm{m}^{2} /$ week. Two dose-limiting toxicities (DLT) occurred at $2.0 \mathrm{mg} / \mathrm{m}^{2} /$ week including one grade 3 febrile neutropenia and one grade 4 neutropenia. Consequently, the MTD was $1.4 \mathrm{mg} / \mathrm{m}^{2} /$ week. Other serious nonhematologic toxicities included hypoglycemia, hypophosphatemia, and fatigue. Responses included two partial responses (lung, bladder) and three minor responses (lung, breast, and thyroid). Stable disease as best response was reported in 12 patients lasting a median of 4 months (range 2-14). Fluorescent immunohistochemical analysis of serial tumor biopsies in 13 patients treated at the MTD demonstrated disruption of microtubule structure in vivo with eribulin treatment. ${ }^{17}$

A subsequent Phase I trial reported by Goel et $\mathrm{al}^{18}$ enrolled patients with advanced solid malignancies. Eribulin dosing began at $0.25 \mathrm{mg} / \mathrm{m}^{2}$ over 1 hour on days 1,8 , and 15 of a 28-day cycle with escalation guided by DLTs. Thirty-two patients received eribulin $\left(0.25,0.5,0.7,1.0\right.$, or $\left.1.4 \mathrm{mg} / \mathrm{m}^{2}\right)$. Patients had received a median of two prior chemotherapeutic

Table I Review of Phase I clinical trials of eribulin in advanced solid tumors

\begin{tabular}{|c|c|c|c|c|c|}
\hline Author & $\mathbf{n}$ & Treatment & RR, n (\%) & SD, n (\%) & Dose-limiting toxicities \\
\hline Synold et al ${ }^{17}$ & 40 & $\begin{array}{l}\text { Eribulin } 0.125-2 \mathrm{mg} / \mathrm{m}^{2} \text { over } 2 \text { minutes on days } \\
\mathrm{I}, 8,15 \text { every } 28 \text { days }\end{array}$ & $2(5)$ & $12(32)$ & Febrile neutropenia, neutropenia \\
\hline Goel et $\mathrm{al}^{18}$ & 32 & $\begin{array}{l}\text { Eribulin } 0.25-1.4 \mathrm{mg} / \mathrm{m}^{2} \text { over I hour on days } \\
\mathrm{I}, 8, \mathrm{I} 5 \text { every } 28 \text { days }\end{array}$ & I (3) & $10(31)$ & Neutropenia \\
\hline Tan et $\mathrm{al}^{19}$ & 21 & Eribulin $0.25-4 \mathrm{mg} / \mathrm{m}^{2}$ over I hour every 21 days & $\mathrm{I}(5)$ & $12(57)$ & Febrile neutropenia, neutropenia \\
\hline Minami et $\mathrm{al}^{26}$ & 15 & $\begin{array}{l}\text { Eribulin } 0.7-2 \mathrm{mg} / \mathrm{m}^{2} \text { over } 5 \text { minutes on days } \\
\mathrm{I} \text { and } 8 \text { every } 2 \mathrm{I} \text { days }\end{array}$ & $3(20)$ & $3(20)$ & Febrile neutropenia, neutropenia \\
\hline Goel et $\mathrm{al}^{27}$ & 21 & $\begin{array}{l}\text { Eribulin } 0.7-1.4 \mathrm{mg} / \mathrm{m}^{2} \text { with gemcitabine } \\
800-1000 \mathrm{mg} / \mathrm{m}^{2} \text { on days I, } 8,15 \text { every } 28 \text { days. } \\
\text { Due to DLT, changed to days I and } 8 \text { every } 2 \mathrm{I} \text { days }\end{array}$ & I (5) & $8(38)$ & $\begin{array}{l}\text { Grade } 3 \text { diarrhea, dizziness, } \\
\text { fatigue }\end{array}$ \\
\hline Swami et $\mathrm{al}^{28}$ & 52 & $\begin{array}{l}\text { Eribulin } 0.7-1.4 \mathrm{mg} / \mathrm{m}^{2} \text { over } 2-5 \text { minutes on days I and } 8 \\
\text { with carboplatin AUC } 5-6 \text { on day I every } 2 \text { I days. }\end{array}$ & $3(6)$ & NR & Febrile neutropenia, neutropenia \\
\hline
\end{tabular}

Abbreviation: NR, not reported. 
regimens (range 1-13), of which $62.5 \%$ had prior vinca alkaloid or taxane treatment. The principal DLT was neutropenia at $1.4 \mathrm{mg} / \mathrm{m}^{2}$ observed in two patients with grade 4 neutropenia, one of whom developed grade 3 fatigue. Three additional patients developed grade 3 neutropenia, and the day 15 treatment of cycle 1 was not given. Thus, the MTD was determined as $1.0 \mathrm{mg} / \mathrm{m}^{2}$. Overall, eribulin showed a manageable toxicity profile with the most common eribulin-related adverse effects due to fatigue (53\% overall, $13 \%$ grade 3 , no grade 4$)$, nausea ( $41 \%$, all grade $1 / 2)$, and anorexia (38\% overall, 3\% grade 3, no grade 4 ). Eight patients $(25 \%)$ reported grade $1 / 2$ neuropathy, and no grade 3/4 neuropathy events were seen. Responses included stable disease in ten patients, ranging from 39 to 234 days, and an unconfirmed partial response in one patient with cervical cancer, lasting 79 days. ${ }^{18}$

Tan et $\mathrm{al}^{19}$ reported a similar Phase I trial of eribulin administered to 21 patients with advanced solid tumors. Eribulin was given as a 1-hour IV infusion every 21 days using an accelerated titration design at doses of $0.25,0.5,1$, 2, 2.8 , and $4 \mathrm{mg} / \mathrm{m}^{2}$. All three patients experienced a DLT of febrile neutropenia at the $4 \mathrm{mg} / \mathrm{m}^{2}$ dose level. The dose was reduced to $2.8 \mathrm{mg} / \mathrm{m}^{2}$, in which two of three patients developed febrile neutropenia. At $2 \mathrm{mg} / \mathrm{m}^{2}$, one of seven patients experienced a neutropenic DLT, and this dose level was defined as the MTD. Grade 3/4 neutropenia occurred in $33 \%$ at $7-15$ days after the first treatment with recovery to normal by the end of the 21-day cycle. Twenty-four percent of patients developed a grade 1 anemia at doses greater than $0.5 \mathrm{mg} / \mathrm{m}^{2}$. Eleven patients received growth factor support. The most frequently reported nonhematologic drugrelated adverse effects were alopecia (33\%), fatigue $(33 \%$, all grade $1 / 2)$, nausea (19\%, all grade 1$)$, and anorexia (14\%, all grade 1/2). Notably, neuropathy was not predominant in this study with only one patient in the $4 \mathrm{mg} / \mathrm{m}^{2}$ cohort experiencing a grade 1 neuropathy. Seven patients developed nine serious adverse effects including one case of grade 3 hyponatremia, one case of grade 3 infection, and six cases of grade 4 febrile neutropenia. Though there were no complete responses, 12 patients experienced stable disease for a median duration of 86 days (range 47 to 386). Of these 12 patients, four had received prior taxane treatment. One patient with non-small cell lung cancer with no prior taxane exposure achieved an unconfirmed partial response after four cycles of eribulin at the $4 \mathrm{mg} / \mathrm{m}^{2}$ dose. One patient died of progressive disease. ${ }^{19}$

Minami et al reported a Phase I study in Japanese patients with refractory solid cancers. Fifteen patients received eribulin as a 2-10 minute IV bolus in doses ranging $0.7-2.0 \mathrm{mg} / \mathrm{m}^{2}$ on days 1 and 8 of a 21-day cycle. Patients were extensively pretreated with a median of 4 (range 1-7) prior chemotherapeutic regimens; $47 \%$ had received taxane therapy. The principal DLT was neutropenia, observed in all three patients treated at $2.0 \mathrm{mg} / \mathrm{m}^{2}$ and in all six patients at $1.4 \mathrm{mg} / \mathrm{m}^{2}$. Two of three patients developed grade 3 febrile neutropenia in the $2.0 \mathrm{mg} / \mathrm{m}^{2}$ and three of six patients in the $1.4 \mathrm{mg} / \mathrm{m}^{2}$ cohort, establishing the MTD as $2.0 \mathrm{mg} / \mathrm{m}^{2}$ and the recommended dose for Phase II studies as $1.4 \mathrm{mg} / \mathrm{m}^{2}$. All neutropenic events were reversible, and the schedule of administering eribulin on days 1 and 8 of a 21-day cycle allowed sufficient time for resolution of grade 3/4 neutropenia prior to the next cycle. Most common nonhematologic toxicities included fatigue (33\% overall, 13\% grade 3, no grade 4 ), hyperglycemia (40\% all grade 2$)$, and alopecia (20\% all grade 2$)$. Partial responses were seen in three patients at the $1.4 \mathrm{mg} / \mathrm{m}^{2}$ dose level. Stable disease was observed in four patients including two with breast cancer. ${ }^{26}$

Phase I studies combining eribulin with a cytotoxic drug were also undertaken. Twenty-one patients with advanced solid tumors received eribulin and gemcitabine. One partial response in an ovarian cancer patient was seen. Stable disease was achieved in eight patients (38\%). DLTs were grade 3 diarrhea, dizziness, and fatigue. Grade 3/4 hematologic toxicities included neutropenia (29\%) and thrombocytopenia (10\%). The doses recommended for Phase II studies were eribulin $1.0 \mathrm{mg} / \mathrm{m}^{2}$ and gemcitabine $1000 \mathrm{mg} / \mathrm{m}^{2}$ every 3 weeks. ${ }^{27}$ In a Phase II study, 52 patients with advanced solid malignancies received eribulin and carboplatin. DLTs included febrile neutropenia and neutropenia. Most frequent grade $3 / 4$ adverse events were neutropenia (40\%), thrombocytopenia (13\%), and fatigue (4\%). One complete response was observed in tonsillar cancer and two partial responses in prostate cancer. The recommended doses for further Phase II investigation were eribulin $1.1 \mathrm{mg} / \mathrm{m}^{2}$ and carboplatin AUC $6 .^{28}$

In these Phase I trials, eribulin demonstrated a manageable toxicity profile and promising anti-cancer activity. Neutropenia was the main DLT despite variations in dosing and administration but was easily reversible.

\section{Phase II studies in MBC}

Three Phase II trials were subsequently conducted in women with heavily pretreated breast cancer (Table 2). Vahdat et al reported a single-arm, open-label, multicenter Phase II study enrolling 103 patients with $\mathrm{MBC}$ with previous anthracycline and taxane therapy. Eribulin $1.4 \mathrm{mg} / \mathrm{m}^{2}$ was administered 
Table 2 Summary of Phase II trials of eribulin in metastatic breast cancer

\begin{tabular}{|c|c|c|c|c|c|c|}
\hline Study & $\begin{array}{l}\text { Protocol } \\
\text { population }\end{array}$ & ORR (\%) & SD (\%) & $\begin{array}{l}\text { Median PFS } \\
\text { (months) }\end{array}$ & $\begin{array}{l}\text { Median OS } \\
\text { (months) }\end{array}$ & Grade $3 / 4$ adverse events \\
\hline Vahdat et $\mathrm{al}^{29}$ & 87 & 11.5 & 42.5 & 2.6 & 9 & $\begin{array}{l}\text { Neutropenia }(64 \%) \text {, febrile neutropenia } \\
(4 \%) \text {, fatigue }(5 \%)^{*} \text {, peripheral } \\
\text { neuropathy }(5 \%)^{*}\end{array}$ \\
\hline Cortes et $\mathrm{al}^{30}$ & 269 & 9.3 & 46.5 & 2.6 & 10.4 & $\begin{array}{l}\text { Neutropenia }(54 \%) \text {, febrile neutropenia } \\
(6 \%) \text {, fatigue }(10 \%)^{*} \text {, peripheral } \\
\text { neuropathy }(7 \%)^{*}\end{array}$ \\
\hline $\mid$ wata et $\mathrm{al}^{3 \mid}$ & 81 & 21.3 & 37.5 & 3.7 & 10.9 & $\begin{array}{l}\text { Neutropenia (95\%), febrile neutropenia } \\
\text { (14\%), peripheral neuropathy }(4 \%)^{*}\end{array}$ \\
\hline
\end{tabular}

Note: *No grade 4 events.

Abbreviations: ORR, overall objective response rate (CR + PR); SD, stable disease; PFS, progression-free survival; OS, overall survival; CR, complete response; PR, partial response.

as an IV infusion over 2-5 minutes on days 1,8 , and 15 of a 28-day cycle. An assessment of toxicity indicated that patients were experiencing neutropenia on day 15 , and a second cohort of 33 patients received eribulin, only on days 1 and 8 of a 21-day cycle. The primary endpoint was objective response rate (ORR). The median age was 55, and 54\% of patients had an Eastern Cooperative Oncology Group (ECOG) performance status of one at baseline. Patients had received extensive treatment with a median of four prior chemotherapy regimens (range 1-11). Patients in the 28-day cohort received a median of 2.5 cycles of eribulin compared with a median of 4 in the 21-day cohort. In the 28 -day cohort, $63 \%$ of patients experienced dose interruptions, delays, reductions, or omissions primarily due to neutropenia during cycle 1 , compared to $18 \%$ of patients in the 21-day cohort. Eighty-seven patients who met the key inclusion criteria were included in the per protocol (PP) population. In the PP population, the ORR by independent review was $10.2 \%$ and $14.3 \%$ in the 28 - and 21 -day cohorts, respectively, yielding an overall ORR of $11.5 \%$ (95\% CI: 5.7-20.1). In the intent-to-treat (ITT) population, the ORR was $13.6 \%$ (95\% CI: 7.6-21.8) by independent review. The clinical benefit rates (CBR), defined as complete and partial responses plus stable disease for $\geq 6$ months, in the 28 - and 21 -day cohorts were $11.9 \%$ and $28.6 \%$, respectively, yielding an overall CBR of $17.2 \%$ (95\% CI: $10.0-26.8)$ in the PP population. The median duration of response was 5.6 months (range 1.4-11.9). The median PFS was 2.6 months (range 0.03-14.9) and the 6-month PFS rate was 25.9\% (95\% CI: 15.5-36.3). The median OS was 9.0 months (range 0.5-27.1). The 6-month and 1-year survival rates were 67.8\% (95\% CI: 58.0-77.6) and 45.7\% (95\% CI: 35.2-56.2), respectively. In exploratory analysis, eribulin appeared to have activity across all subgroups including those treated with four or more regimens. ${ }^{29}$
The most frequent toxicities included neutropenia $(75 \%$ overall, $64 \%$ grade $3 / 4$ ), fatigue ( $52 \%$ overall, $5 \%$ grade 3 , no grade 4 ), nausea ( $37 \%$ overall, $1 \%$ grade 3 , no grade 4 ), and anorexia ( $15 \%$, only grade $1 / 2)$. The incidence of febrile neutropenia was low, only occurring in $4 \%$ of patients. Fifty-three percent and $50 \%$ of patients received erythrocyte and granulocyte growth factors, respectively. Forty-one percent of patients reported alopecia, however the presence of alopecia at baseline was not recorded. Only five patients (5\%) experienced grade 3 peripheral neuropathy, of which four were in the 28-day cohort. No grade 4 neuropathy events were reported. Overall, the 21-day schedule appeared to be better tolerated than the 28-day schedule, with less neuropathy, anorexia, anemia, and thrombocytopenia. ${ }^{29}$

Cortes et al reported a subsequent single-arm, open-label, multicenter Phase II trial of eribulin enrolling 299 patients with locally advanced and MBC who had previously received an anthracycline, taxane, and capecitabine. Eribulin $1.4 \mathrm{mg} / \mathrm{m}^{2}$ was administered as a 2-5 minute IV infusion on days 1 and 8 of a 21-day cycle to 291 patients. The primary end point was ORR. Patients were extensively pretreated with a median of four chemotherapy regimens. The median age was 56, and $63 \%$ had an ECOG score of 1 or 2 . Patients received a median of four cycles (range 1-27). Of the 291 patients treated with eribulin, $21 \%$ experienced treatment delays, $8.6 \%$ experienced dose omissions, and $3.4 \%$ had dose reductions in cycle 1, primarily due to neutropenia. This low number of dose reductions suggested that the 21-day dosing schedule was more optimal than the 28-day dosing schedule used in the prior Phase II study. In the 269 patients who met the key inclusion criteria for primary efficacy analysis, the independently reviewed ORR was $9.3 \%$ (95\% CI: 6.1-13.4) and the CBR was $17.1 \%$ (95\% CI: 12.8-22.1). In the ITT population, the independently reviewed ORR and CBR were $9.3 \%(95 \%$ CI: 6.2-13.2) and 17.2\% (95\% CI: 13.0-22.0), respectively. 
The median duration of response was 4.1 months (range 1.4-8.5). The median PFS was 2.6 months (range 0.03-13.1), and the 6-month PFS rate was $15.6 \%$ (95\% CI: 10.7-20.5). The median OS was 10.4 months (range 0.6-19.9), and the 6-month OS rate was 72.3\% (95\% CI: 66.9-77.6). There was activity across all subgroups, with higher responses in less refractory patients and in hormone receptor positive disease. The most common eribulin-related adverse events were neutropenia ( $60 \%$ overall, $54 \%$ grade $3 / 4$ ), fatigue (65\% overall, $10 \%$ grade 3 , no grade 4$)$, and nausea ( $44 \%$ overall, $2 \%$ grade 3, no grade 4 ). Febrile neutropenia occurred in $5.5 \%$ of patients. Only $7 \%$ of patients reported grade 3 peripheral neuropathy, with no grade 4 incidences. Eribulin did not exacerbate pre-existing grade $1 / 2$ neuropathy. ${ }^{30}$

Another single-arm, open label Phase II study, reported by Iwata et $\mathrm{al}^{31}$ in abstract form, enrolled 84 Japanese patients with locally advanced or MBC previously treated with an anthracycline and a taxane. Of the 81 patients who received eribulin $1.4 \mathrm{mg} / \mathrm{m}^{2}$ as a 2-5 minute IV infusion on days 1 and 8 of a 21-day cycle, the primary endpoint ORR was $21.3 \%$ (95\% CI: 12.9-31.8). There were no complete responses and 17 partial responses. Stable disease was seen in $37.5 \%$ of patients. The median duration of response was 3.7 months (95\% CI: 2.8-4.9). The median PFS was 3.7 months (95\% CI: 2.0-4.4) and 6-month PFS rate was 20.1\%. The median OS was 10.9 months and the 6-month OS rate was $72.3 \%$. The most frequent treatment-related grade $3 / 4$ toxicities were neutropenia (95\%), leukopenia (74\%), and febrile neutropenia (14\%). Grade 3 peripheral neuropathy occurred in $3.7 \%$ of patients (no grade 4$){ }^{31}$

These Phase II studies demonstrated that eribulin was active in a heavily pretreated breast cancer population. Toxicities recapitulated those seen in the Phase I studies.

\section{Phase III studies in MBC}

The Phase III trial, Eisai Metastatic Breast Cancer Study Assessing Physician's Choice Versus E7389 (EMBRACE; E 305, NCT00388726) was a global, multicenter, openlabel, randomized study which established eribulin as a new potential standard treatment for heavily pretreated MBC (Table 3). ${ }^{7}$ In this study, 762 women with locally recurrent or MBC were randomly allocated in a 2:1 ratio to eribulin $1.4 \mathrm{mg} / \mathrm{m}^{2}$ over $2-5$ minutes on days 1 and 8 of a 21 -day cycle $(n=508)$ or treatment of physician's choice (TPC; $n=254)$. Randomization was stratified by geographical region, previous capecitabine treatment, and human epidermal growth factor receptor 2 (HER2) status. TPC was defined as any singleagent chemotherapy, hormonal, or biologic treatment, or best supportive care alone. Tumor assessments were evaluated according to Response Evaluation Criteria in Solid Tumors (RECIST) every 8 weeks, or sooner if disease progression was suspected. The primary endpoint was overall survival in the ITT population.

The median age was 55 years (range 27-85), and majority of patients (49\%) had an ECOG score of one. Patients were extensively pretreated, having received a median of four prior chemotherapy regimens (range 1-7) including an anthracycline and a taxane, unless contraindicated. Most were considered refractory to taxanes ( $81 \%$ of patients), capecitabine (68\%), and/or anthracyclines (58\%), defined as progression on or within 6 months of receiving treatment. Overall, 16\% of patients had HER2-positive breast cancer and 19\% had triple-negative (ER-negative, PR-negative, HER2-negative) disease. The most common metastatic sites were bone $(61 \%$ of patients) and liver (60\%), and 51\% had at least three organ sites involved. Most TPC patients received chemotherapy $(96 \%)$ including vinorelbine (26\%), gemcitabine (18\%),

Table 3 Results of Phase III EMBRACE trial

\begin{tabular}{llll}
\hline & Eribulin & TPC & P value \\
\hline Intent-to-treat population, $\mathbf{n}$ & 508 & 254 \\
Median OS (months) & 13.1 & 10.6 & $9.3-12.5$ \\
$95 \% \mathrm{Cl}$ & $11.8-14.3$ & 2.2 & 0.04 \\
Median PFS (months) & 3.7 & $2.1-3.4$ \\
$95 \% \mathrm{Cl}$ & $3.3-3.9$ & 214 \\
Response evaluable population, $\mathbf{n}$ & 468 & $4.7(2.3-8.4)$ \\
Objective response rate (CR + PR), \% & $12.2(9.4-15.5)$ & $17(12.1-22.5)$ \\
Clinical benefit rate (CR + PR + SD $\geq 6$ months), \% & $23(18.9-26.7)$ & \\
Common grade 3/4 toxicities (\%) & & $21(2)$ \\
Neutropenia (febrile neutropenia) & $45(5)$ & $10 *$ \\
Asthenia/fatigue & 9 & $2 *$ \\
Peripheral neuropathy & 8 & 0.002 \\
\hline
\end{tabular}

Note: *No grade 4.

Abbreviations: SD, stable disease; PFS, progression-free survival; OS, overall survival; CR, complete response; PR, partial response. 
capecitabine $(18 \%)$, taxanes $(15 \%)$, and anthracyclines $(10 \%)$ representing real-life treatment decisions at the time (2006-2008). Four percent received sole hormone therapy and no patients received supportive care alone. The median duration of eribulin treatment and TPC was 3.9 months (range 0.7-16.3) and 2.1 months (range 0.03-21.2) for those receiving chemotherapy, respectively. Dose interruptions, delays, or reductions occurred in 421 (84\%) patients in the eribulin group compared to $182(76 \%)$ in the chemotherapy TPC groups, primarily due to neutropenia.

The study met its primary endpoint, showing a significant increase in OS for eribulin (13.1 months, 95\% CI: 11.8-14.3) compared with TPC (10.6 months, 95\% CI: 9.3-12.5; HR: 0.81, 95\% CI: $0.66-0.99, P=0.041)$ in the ITT population. The median PFS in the eribulin-treated and the TPC groups was 3.7 months (95\% CI: 3.3-3.9) and 2.2 months (range 2.1-3.4), respectively (HR: $0.87,95 \% \mathrm{CI}: 0.71-1.05$, $P=0.137)$ by independent review. Investigator assessment demonstrated a similar but significant median PFS (HR: $0.76,95 \%$ CI: $0.64-0.90, P=0.002$ ), likely due to less censored patients with the investigator versus independent review (127 vs 241), resulting in more progression events with investigator assessment (635 vs 521). The PP population revealed significant improvements in PFS with eribulin treatment in both independent and investigator reviews. The ORR with eribulin was $12 \%$ (95\% CI: 9.4-15.5) compared to 5\% (95\% CI: $2.3-8.4)$ with TPC $(P=0.002)$ by independent review. The CBR similarly favored eribulin $(23 \%$, 95\% CI: 18.9-26.7) over TPC (17\%, 95\% CI: 12.1-22.5). Three patients in the eribulin group experienced a complete response, and none were seen with TPC. Exploratory subgroup analyses did not find any important differences in clinical efficacy except for a significantly longer survival for patients treated in North America, Western Europe, and Australia.

Eribulin was well tolerated consistent with earlier studies. Though adverse events occurred in $99 \%$ of patients receiving eribulin, the majority was grade 1 or 2 . Frequent toxicities included neutropenia (eribulin, 52\% vs TPC, 30\%), fatigue (54\% vs $40 \%$ ), nausea (35\% vs $28 \%$ ), and peripheral neuropathy (35\% vs 16\%). Granulocyte colony stimulating factor was given to $18 \%$ in the eribulin group and $8 \%$ in the TPC group. Febrile neutropenia was uncommon $(5 \%$ with eribulin vs $2 \%$ with TPC). Whereas $<1 \%$ of patients discontinued eribulin due to hematologic toxicity, peripheral neuropathy led to eribulin discontinuation in 5\% of patients. Nonetheless, neuropathy improved to grade 2 or lower after delays or dose reductions of eribulin in patients with grade
3 or 4 neuropathy. The incidence of neuropathy with eribulin was similar to the taxane subgroup.

EMBRACE has been the only Phase III study in MBC to define OS as the primary endpoint and meet it. Furthermore, no study in MBC has included such a heavily pretreated population. Based on the 2.5 month extension of median survival representing a $23 \%$ increase in survival with eribulin over TPC alongside a manageable side effect profile, the authors concluded that eribulin could become a potential new standard of care for heavily treated MBC patients. The results of this study led to the regulatory approval of eribulin in the US as third-line treatment of MBC after anthracycline and taxane failure. ${ }^{7}$ A subsequent Phase III trial (E 301) completed accrual of 1102 patients with locally advanced or MBC previously treated with anthracylines or taxanes, comparing eribulin to capecitabine. The primary endpoints are OS and PFS. Results are awaited. ${ }^{32}$

\section{Patient-focused perspectives}

Eribulin was well tolerated by breast cancer patients. The majority of dose reductions, delays, or omissions were due to neutropenia rather than clinical symptoms. Peripheral neuropathy remains a concern facing breast cancer patients and treating oncologists alike, as the incidence and severity tend to be cumulative and no standard therapy for prevention or management exists. Other microtubule-targeted agents used in the management of breast cancer, including the taxanes and epothilones, are fraught with the development of severe (grade $3 / 4$ ) neuropathy in as many as $30 \%$ of patients during their treatment course. ${ }^{33}$ Eribulin was associated with a low incidence of neuropathy in breast cancer clinical trials $(27 \%-35 \%$ all grades, $3 \%-8 \%$ grade $3 / 4)$ though it is important to note that patients with pre-existing neuropathy above grade 2 were excluded from these trials. ${ }^{7,29,30}$ Eribulin did not appear to worsen pre-existing grade 1 or 2 peripheral neuropathy. ${ }^{30}$ Interestingly, mouse models demonstrated that eribulin induced less neuropathy than paclitaxel or ixabepilone at equivalent MTD-based doses. ${ }^{34}$ The impact of eribulin versus ixabepilone on neuropathy is being investigated in MBC patients with prior taxane use (ClinicalTrials.gov identifier: NCT00879086). Eribulin also has a short infusion time and does not require premedications to prevent hypersensitivity reactions.

Exploratory analysis of QOL parameters from the Phase II MBC study indicated no deterioration or improvement in symptomatology among patients whose tumors responded to eribulin, although patients with progression experienced a marked symptomatic deterioration by the end 
Table 4 Ongoing/pending clinical trials evaluating eribulin in metastatic breast cancer

\begin{tabular}{|c|c|c|c|c|c|}
\hline $\begin{array}{l}\text { ClinicalTrials.gov } \\
\text { identifier (study name) }\end{array}$ & Phase & Eligibility & Intervention & Primary endpoint(s) & Status \\
\hline \multicolumn{6}{|l|}{ Second-line and beyond } \\
\hline NCT00337I03 (E 30I) & III & $\begin{array}{l}\text { Prior treatment with } \\
\text { anthracycline and taxane }\end{array}$ & Eribulin vs capecitabine & OS, PFS & Completed accrual \\
\hline NCTOI427933 & II & $\begin{array}{l}\text { Prior treatment with } \\
\text { anthracycline and taxane }\end{array}$ & $\begin{array}{l}\text { Ramucirumab with } \\
\text { eribulin vs eribulin } \\
\text { monotherapy }\end{array}$ & PFS & Not yet recruiting \\
\hline NCT00879086 (E 209) & II & $\begin{array}{l}\text { Prior treatment with } \\
\text { a taxane }\end{array}$ & Eribulin vs ixabepilone & $\begin{array}{l}\text { Percent of subjects with } \\
\text { neuropathy adverse events }\end{array}$ & Completed accrual \\
\hline \multicolumn{6}{|l|}{ First-line therapy } \\
\hline NCTOI268I50 (E 206) & II & HER2-negative disease & Eribulin & ORR & Recruiting \\
\hline NCT0I 269346 (E 208) & II & HER2-positive disease & Eribulin with trastuzumab & ORR & Recruiting \\
\hline
\end{tabular}

Abbreviations: ORR, overall objective response rate (CR + PR); PFS, progression-free survival; OS, overall survival.

of treatment. ${ }^{30}$ Due to the design of the EMBRACE Phase III study, it was not possible to capture QOL data, therefore it is difficult to assess if the adverse effects experienced by the patients was balanced by the 2.5-month survival extension. The E 301 study comparing second-line eribulin to capecitabine in MBC patients includes a formal QOL assessment as a secondary objective. ${ }^{32}$

\section{Conclusion}

Eribulin has demonstrated remarkable Phase III clinical activity for the treatment of MBC refractory to an anthracycline and a taxane. Its unique mechanism of action likely enhances its ability to overcome chemo-resistance. Furthermore, eribulin has a manageable side effect profile, a low incidence of peripheral neuropathy, tolerance at full doses in renal dysfunction, and lack of drug-drug interactions or hypersensitivity. Several clinical trials evaluating eribulin in locally recurrent or $\mathrm{MBC}$ as monotherapy and in combination with biologic agents are ongoing (Table 4) ${ }^{35}$ Eribulin is also being investigated in Phase II studies of early stage breast cancer, eg, dose dense doxorubicin and cyclophosphamide followed by eribulin in HER2positive disease (NCT01328249) and neoadjuvant eribulin and carboplatin in triple-negative patients (NCT01372579).

Eribulin has demonstrated clinical efficacy in several other malignancies including non-small cell lung cancer, urothelial tract cancer, and sarcoma. ${ }^{36-38}$ Active trials in advanced lung cancer include eribulin in combination with pemetrexed (NCT01126736) and erlotinib (NCT01104155) in previously treated disease, as well as first-line eribulin as monotherapy (NCT00400829). The safety of eribulin in renal dysfunction is being further studied in patients with metastatic urothelial tract cancer (NCT00365157). A randomized, open-label, multicenter, Phase III trial is investigating eribulin and dacarbazine in soft tissue sarcomas (NCT01327885).
To help guide future studies, the identification of predictive biomarkers is sorely needed. Nonetheless, eribulin has become an important addition to the breast cancer treatment armamentarium.

\section{Disclosure}

The authors report no conflicts of interest in this work.

\section{References}

1. Jemal A, Bray F, Center MM, et al. Global cancer statistics. CA Cancer J Clin. 2011;61:69-90.

2. Brewster AM, Hortobagyi GN, Broglio KR, et al. Residual risk of breast cancer recurrence five years after adjuvant therapy. J Natl Cancer Inst. 2008;100:1179-1183.

3. Jemal A, Siegel R, Xu J, et al. Cancer statistics, 2010. CA Cancer J Clin. 2010;60:277-300

4. O'Shaughnessy J, Miles D, Vukelja S, et al. Superior survival with capecitabine plus docetaxel combination therapy in anthracyclinepretreated patients with advanced breast cancer: phase III trial results. J Clin Oncol. 2002;20:2812-2823.

5. Thomas ES, Gomez HL, Li RK, et al. Ixabepilone plus capecitabine for metastatic breast cancer progressing after anthracycline and taxane treatment. J Clin Oncol. 2007;25:5210-5217.

6. Sparano JA, Vrdoljak E, Rixe O, et al. Randomized phase III trial of ixabepilone plus capecitabine versus capecitabine in patients with metastatic breast cancer previously treated with an anthracycline and a taxane. J Clin Oncol. 2010;28:3256-3263.

7. Cortes J, O'Shaughnessy J, Loesch D, et al. Eribulin monotherapy versus treatment of physician's choice in patients with metastatic breast cancer (EMBRACE): a phase 3 open-label randomised study. Lancet. 2011;377:914-923.

8. Hirata Y, Uemura D. Halichondrins-antitumor polyether macrolides from a marine sponge. Pure Appl Chem. 1986;58:701-710.

9. Bai RL, Paull KD, Herald CL, et al. Halichondrin B and homohalichondrin $\mathrm{B}$, marine natural products binding in the vinca domain of tubulin. Discovery of tubulin-based mechanism of action by analysis of differential cytotoxicity data. J Biol Chem. 1991;266: 15882-15889.

10. Towle MJ, Salvato KA, Budrow J, et al. In vitro and in vivo anticancer activities of synthetic macrocyclic ketone analogues of halichondrin B. Cancer Res. 2001;61:1013-1021.

11. Aicher TD, Buszek KR, Fang FG, et al. Total synthesis of halichondrin B and norhalichondrin B. J Am Chem Soc. 1992;114: 3162-3164. 
12. Jordan MA, Kamath K, Manna T, et al. The primary antimitotic mechanism of action of the synthetic halichondrin E7389 is suppression of microtubule growth. Mol Cancer Ther. 2005;4:1086-1095.

13. Alday PH, Correia JJ. Macromolecular interaction of halichondrin B analogues eribulin (E7389) and ER-076349 with tubulin by analytical ultracentrifugation. Biochemistry. 2009;48:7927-7938.

14. Kuznetsov G, TenDyke K, Yu M, et al. Antiproliferative effects of halichondrin B analog eribulin mesylate (E7389) against paclitaxel-resistant human cancer cells in vitro. Proc Am Assoc Cancer Res. 2007:C58.

15. Kuznetsov G, Towle MJ, Cheng H, et al. Induction of morphological and biochemical apoptosis following prolonged mitotic blockage by halichondrin B macrocyclic ketone analog E7389. Cancer Res. 2004;64:5760-5766.

16. Okouneva T, Azarenko O, Wilson L, et al. Inhibition of centromere dynamics by eribulin (E7389) during mitotic metaphase. Mol Cancer Ther. 2008;7:2003-2011.

17. Synold TW, Morgan RJ, Newman EM, et al. A Phase I pharmacokinetic and target validation study of the novel anti-tubulin agent E7389: a California Cancer consortium trial [abstract 3036]. J Clin Oncol. 2005;23(Suppl):3036.

18. Goel S, Mita AC, Mita M, et al. A phase I study of eribulin mesylate (E7389), a mechanistically novel inhibitor of microtubule dynamics, in patients with advanced solid malignancies. Clin Cancer Res. 2009; 15:4207-4212.

19. Tan AR, Rubin EH, Walton DC, et al. Phase I study of eribulin mesylate administered once every 21 days in patients with advanced solid tumors. Clin Cancer Res. 2009;15:4213-4219.

20. Synold T, Tsao-Wei D, Quinn D, et al. Phase I and pharmacokinetic (PK) study of eribulin (E7389) in patients (pts) with renal dysfunction (RD) and advanced urothelial cancer (UC): A California Cancer Consortium Trial [abstract]. J Clin Oncol. 2010;28(Suppl):Abst 2527.

21. Witteveen P, Marchetti S, Mergui-Roelvink M, et al. Eribulin mesylate pharmacokinetics in patients with hepatic impairment [abstract]. J Clin Oncol. 2010;28(Suppl):Abst 2582.

22. Zhang ZY, King BM, Pelletier RD, et al. Delineation of the interactions between the chemotherapeutic agent eribulin mesylate (E7389) and human CYP3A4. Cancer Chemother Pharmacol. 2008;62:707-716.

23. Devriese L, Wanders J, Jenner A, et al. Eribulin mesylate pharmacokinetics in patients with solid tumors receiving repeated oral ketoconazole [abstract]. EORTC-NCI-AACR Symposium. 2010;8(181):Abst 574.

24. Zheng W, Seletsky B, Palme M, et al. Structure-activity relationships of synthetic halicondrin B analog E7389: in vitro susceptibility to PgPmediated drug efflux [abstract]. Proc Am Assoc Cancer Res. 2003;7:Abst 2751.
25. Agoulnik S, Kuznetsov G, Tendyke K, et al. Sensitivity to halichondrin analog E7389 and hemiasterlin analog E7974 correlates with BIII tubulin isotype expression in human breast cancer cell lines. J Clin Oncol. 2005;23:2012.

26. Minami H, Mukohara T, Nagai S, et al. A phase I study of eribulin mesylate (E7389) in patients with refractory cancers. Eur J Cancer Suppl. 2008;6:140.

27. Goel R, Chen E, Welch S, et al. Phase I study of E7389/gemcitabine combination in patients with advanced solid tumors [abstract]. J Clin Oncol. 2009;27(Suppl):Abst e13509.

28. Swami U, Petrylak DP, Raftopoulos H, et al. Phase IB study of eribulin mesylate in combination with carboplatin in patients with advanced solid tumors [abstract]. J Clin Oncol. 2010;28(Suppl):Abstr 2589.

29. Vahdat LT, Pruitt B, Fabian CJ, et al. Phase II study of eribulin mesylate, a halichondrin B analog, in patients with metastatic breast cancer previously treated with an anthracycline and a taxane. J Clin Oncol. 2009;27:2954-2961

30. Cortes J, Vahdat L, Blum JL, et al. Phase II study of the halichondrin B analog eribulin mesylate in patients with locally advanced or metastatic breast cancer previously treated with an anthracycline, a taxane, and capecitabine. J Clin Oncol. 2010;28:3922-3928.

31. Iwata H, Aogi K, Masuda N, et al. Efficacy and safety of eribulin in Japanese patients (pts) with advanced breast cancer [abstract]. J Clin Oncol. 2010;28:1081.

32. Twelves C, Cortes J, Vahdat LT, et al. Phase III trials of eribulin mesylate (E7389) in extensively pretreated patients with locally recurrent or metastatic breast cancer. Clin Breast Cancer. 2010;10:160-163.

33. Lee JJ, Swain SM. Peripheral neuropathy induced by microtubulestabilizing agents. J Clin Oncol. 2006;24:1633-1642.

34. Wozniak KM, Nomoto K, Lapidus RG, et al. Comparison of neuropathyinducing effects of eribulin mesylate, paclitaxel, and ixabepilone in mice. Cancer Res. 2011;71:3952-3962.

35. www.ClinicalTrials.gov. Bethesda (MD): National Library of Medicine (US). Accessed September 17, 2011.

36. Spira AI, Iannotti NO, Savin MA, et al. A phase II study of eribulin mesylate (E7389) in patients with advanced, previously treated nonsmall-cell lung cancer. Clin Lung Cancer. 2011. [Epub ahead of print.]

37. Quinn DI, Aparicio A, Tsao-Wei DD, et al. Phase II study of eribulin (E7389) in patients (pts) with advanced urothelial cancer (UC) - Final report: A California Cancer Consortium-led NCI/CTEP-sponsored trial [abstract]. J Clin Oncol. 2010;28:15s(Suppl):Abst 4539.

38. Schoffski P, Ray-Coquard IL, Cioffi A, et al. Activity of eribulin mesylate in patients with soft-tissue sarcoma: a phase 2 study in four independent histological subtypes. Lancet Oncol. 2011;12:1045-1052.
Biologics: Targets \& Therapy

\section{Publish your work in this journal}

Biologics: Targets \& Therapy is an international, peer-reviewed journal focusing on the patho-physiological rationale for and clinical application of Biologic agents in the management of autoimmune diseases, cancers or other pathologies where a molecular target can be identified This journal is indexed on PubMed Central, CAS, EMBase, Scopus

\section{Dovepress}

and the Elsevier Bibliographic databases. The manuscript management system is completely online and includes a very quick and fair peerreview system, which is all easy to use. Visit http://www.dovepress. com/testimonials.php to read real quotes from published authors. 